\title{
The Reform of Engineering Professional Online Education Courses by Artificial Intelligence and Wireless Network Technology in the Context of Engineering Certification
}

\author{
Chang Che (iD, Qiubin Luo, and Yan Mao \\ School of Civil Engineering, Harbin University, Harbin 150086, Heilongjiang, China \\ Correspondence should be addressed to Chang Che; chechang@hrbu.edu.cn
}

Received 28 October 2021; Accepted 22 December 2021; Published 18 February 2022

Academic Editor: Narasimhan Venkateswaran

Copyright (c) 2022 Chang Che et al. This is an open access article distributed under the Creative Commons Attribution License, which permits unrestricted use, distribution, and reproduction in any medium, provided the original work is properly cited.

\begin{abstract}
The problems existing in the online education courses of engineering majors in colleges and universities are studied, and the online education platform under the background of engineering certification is designed and researched. Artificial intelligence (AI) technology and wireless network technology are used in the in-depth study of online education courses. In terms of AI, the storage of data is specifically divided into three levels, namely, the source layer (operational data layer), the historical storage layer, and the data model layer. Data analysis includes the total number of data, spatial scope, and period, etc. The results show that the overall response time of the designed platform to the operation of university teachers and students is controlled within $3 \mathrm{~s}$. The test results of two online education platforms show that the performance of the designed online education platform is relatively stable. It provides hardware support for online curriculum reform. In addition, in terms of the platform test pass rate, after many tests, the online education platform security test pass rate is above $98 \%$. In the end, these conclusions are drawn: AI technology and wireless network technology can effectively improve the performance of online education platforms. Meanwhile, this can also further improve the learning efficiency of online education courses for college engineering students.
\end{abstract}

\section{Introduction}

With the progress of the times, the reform of higher education [1-3] is imperative. Engineering certification is carried out in conjunction with the educational improvement of colleges and universities. This process includes the background of engineering certification, the specific process of college engineering majors and engineering certification [4-6], and the training plan for college engineering students. The purpose of engineering certification is to comprehensively evaluate the teaching management of college teachers, the faculty of teachers, and teaching equipment. Online education refers to the dissemination of knowledge and learning through the Internet and Applied Information Technology. Therefore, engineering certification is a broader concept than online education. In this context, the curriculum reform of online education [7-9] has been pushed to the cusp of teaching reform. The emergence of online courses has provided great convenience for the sharing of teaching resources in different regions. Nowadays, excellent online open courses can be seen on the teaching platforms of various schools [10-12]. Online open courses provide students with low learning efficiency with multiple learning opportunities and to a certain extent, draw the distance between top students and students with average academic performance. Although online education has great convenience and various advantages, its disadvantages still exist. How to make the teaching mode of online education more flexible and the supervision system of the teaching mechanism more perfect, and to further improve the teaching effect of students are the problems that need to be solved now.

Through a lot of research, some effective methods have been discovered. Palvia et al. [13] pointed out the wide application of information and communication technology, the Internet and some information fusion technologies, and 
various modes of online education are growing rapidly and steadily all over the world. They believed that this online education model will become an inseparable part of the education industry in the new world soon. Villegas-Ch et al. [14] proposed to combine data analysis techniques with artificial intelligence (AI) technology to improve students' learning. This method is on a stable education model, using online education as a platform, and trying to let virtual assistants help students. The proposal of this method has changed the way of communication and interaction between teachers and students to a certain extent. Chakraborty et al. [15] have shown that the teaching quality of physical classrooms is better than that of online education. However, as coronavirus disease-19 (COVID-19) is raging around the world, various schools are conducting online education, and students are very interested in learning materials and software for online education. Chen et al. [16] compared the results of online learning and traditional classroom accounting courses. Research results show that online classrooms can also provide better learning results. Liu et al. [17] studied the impact of online continuing dental education under coronavirus disease 2019 (COVID-19). The results show that during the COVID-19 epidemic, China's online dental continuing education has increased significantly. Danchikov et al. [18] studied the potential of online learning under modern conditions and its application at different levels of education and explored the potential of online learning under modern conditions. The results show that under current conditions, the existing resources of educational institutions can effectively transform offline education into online education. Nevertheless, this closed education does affect the normal social life of students. Xu and Zhao [19] studied the collaborative relationship between online education and the wireless network of electronic music creation and performance under AI. They also designed sensor network-related equipment by using a fuzzy clustering algorithm and designed an electronic music creation system by using AI. The simulation results suggested that the mean absolute error (MAE) and mean square error (MSE) of collaborative filtering and fuzzy showed a downward trend on the premise of increasing the number of neighbors. However, when the number of visitors is the same, the filtering matching algorithm is greater than the collaborative filtering algorithm in terms of MAE and MSE. The research transforms the sound characteristics into image structure through an oscilloscope, forms the corresponding sound and image mode, realizes the intelligent matching of online electronic music, and optimizes the effect of online education. Related scholars have studied the actual situation of online education interaction using big data technology and cloud computing. The results show that these two technologies have great advantages for the interactive platform of online education and prove its feasibility [20,21].

Through the above research status, the previous research did not involve the online education reform combining AI and wireless network technology under the background of engineering certification. AI technology and wireless network technology have been deeply researched on the reform of engineering professional online education courses. The

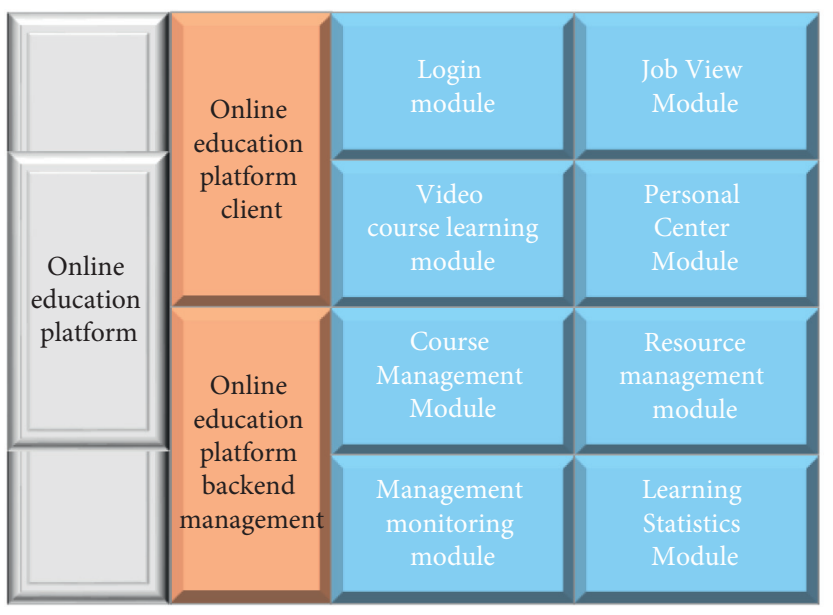

FIgURE 1: The functional framework of the online education platform.

innovation of the online education reform being studied lies in the combination of $\mathrm{AI}$ and wireless network technology, which has not been studied before. The combination of AI and wireless network technology provides theoretical support for the reform of online education courses, which is of great significance.

\section{Materials and Methods}

2.1. AI Technology. This is the probability algorithm that the platform of engineering professional online education courses [22-24] is successfully accessed by college teachers and students. The functions of the engineering professional online education platform are mainly divided into two parts, one is the client of the online education platform, and the other is the backstage management of the online education platform. The first part is divided into four modules, login module, homework viewing module, video course learning module, and personal center module. The second part is also divided into four modules, course management module, resource management module, online monitoring module, and learning data analysis module. Figure 1 is a detailed framework diagram of the functions of the online education platform.

After clicking on the online education course platform for college engineering teachers and students, the specific calculation for the probability of staying on the current page of the platform is shown in the following equation:

$$
p_{1}=(1-\alpha) \frac{1}{N}
$$

In equation (1), $p_{1}$ represents the probability, $\alpha$ represents the transition probability, and $\mathrm{N}$ represents the number of households. College teachers and students perform related operations on the engineering online education platform, and the page jump probability of the platform is calculated as shown in the following equation:

$$
p_{2}=\operatorname{PR}(j) \times \alpha \times \frac{\operatorname{PR}(j)}{|\operatorname{out}(j)|} .
$$




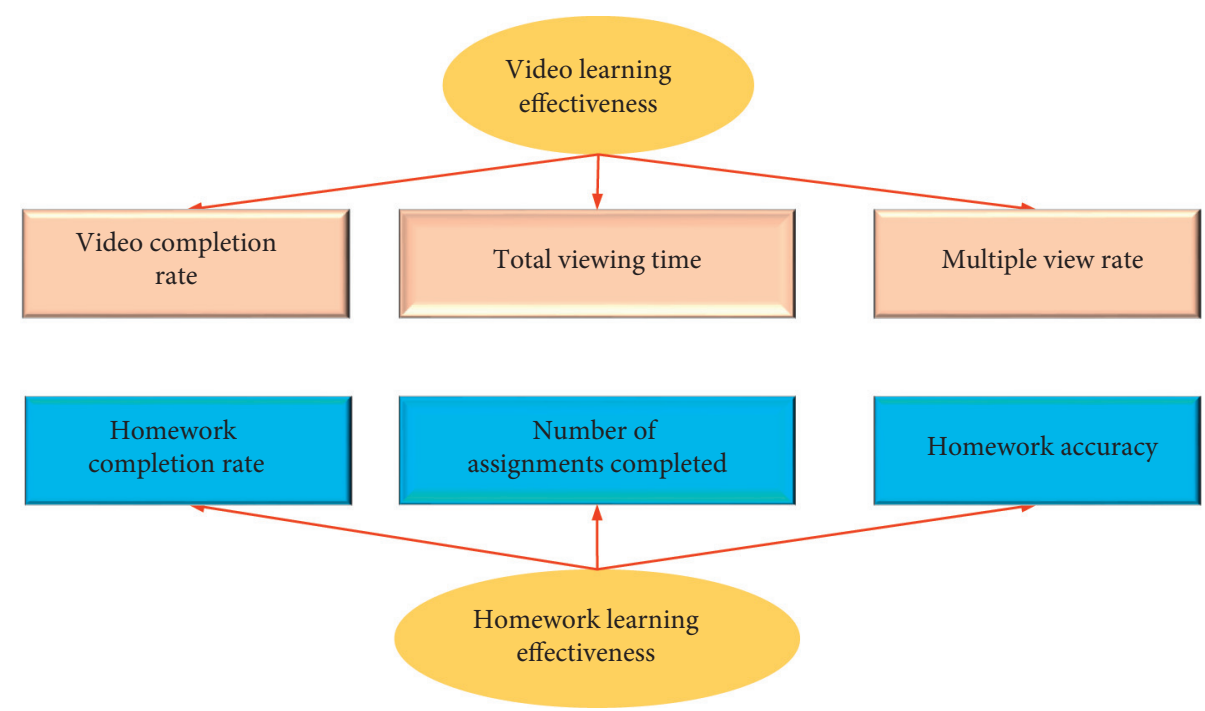

Figure 2: Structure diagram of online learning effectiveness.

From equations (1) and (2), the calculation equation of PageRank (PR) can be obtained, and the specific calculation is as follows:

$$
\operatorname{PR}(i)=\alpha \sum_{j \in i n(i)} \frac{\operatorname{PR}(j)}{|\operatorname{out}(j)|}+\frac{1-\alpha}{N} .
$$

In equation (3), $\mathrm{PR}(i)$ represents the PageRank value of the node of the university teacher and student user on the online education platform. $\alpha$ stands for transition probability. $\mathrm{N}$ represents the number of teachers and students on the online education platform of colleges and universities. in $(i)$ represents a collection of related interfaces $i$ through online education platforms. out $(j)$ stands for the collection of interfaces $j$ pointed to by the interface.

$$
\operatorname{PR}(i)=(1-\alpha) r_{i}+\alpha \sum_{j \in \operatorname{in}(i)} \frac{\operatorname{PR}(j)}{|\operatorname{out}(j)|} .
$$

In equation (4), Personal Rank is the specific form of the evolution of the PageRank algorithm. Among them, when $r_{i}$ is $i=u, r_{i}=1$; when $i \neq u, r_{i}=0$.

$$
F\left(u_{i}\right)=\log _{0.5}\left(\frac{T_{u_{i}}}{10}+1\right)
$$

In equation (5), $T_{u_{i}}$ represents the length of time that teachers and students of engineering majors in colleges and universities use the online education platform in the current time sequence. Regarding the efficiency of student learning on the online education platform, it is expounded from two aspects. The first is the effectiveness of video learning, which is divided into three modules, the completion rate of video learning, the total time spent watching the video, and the video multiple viewing rate. The second is the effectiveness of homework learning, which is also divided into three modules, the completion rate of homework learning, the number of times the homework is completed, and the accuracy of completing the homework. Figure 2 is a structural diagram of the effectiveness of online learning for engineering majors in colleges and universities.

If the length of time the university teachers and students use the online platform cannot be judged, then $F\left(u_{i}\right)=0$, indicating that the impact of the time the university teachers and students use the online education platform on the calculation of Personal Rank (PR) can be ignored. In this case, adding the dynamic time weight, $\mathrm{PR}$ is calculated as follows:

$\operatorname{PR}(i)=(1-\alpha) r_{i}+\alpha \sum_{j \in \operatorname{in}(i)} \frac{\operatorname{PR}(j)}{|\operatorname{out}(j)|}+\log _{0.5}\left(\frac{T_{u_{i}}}{10}+1\right)$.

Online teachers and students of engineering majors in colleges and universities use the online education platform model, as shown in the following equation:

$$
\vec{U}=\left\langle\vec{U}_{1}, \vec{U}_{2}, \ldots, \vec{U}_{n}\right\rangle
$$

In equation (8), $U$ is the node that represents the online education platform used by university teachers and students, and $D$ is the node that the online education platform switches, as shown in the following equation:

$$
V=\left\langle U_{1}, D_{1}\right\rangle \text {. }
$$

The design of the online education platform for engineering majors in colleges and universities is shown in Figure 3. The online education platform is divided into three major frameworks. The first is the presentation framework of the online education platform. The second is the business level of the online education platform. The third is the data support level of the online education platform. These three framework levels are interrelated and indispensable. The online education platform mainly presents a human-computer interaction interface so that teachers and students in colleges and universities can have a good teaching and learning experience. In addition, according to the actual needs of teachers and students, the business level of the online education platform is used for technical issues such as 


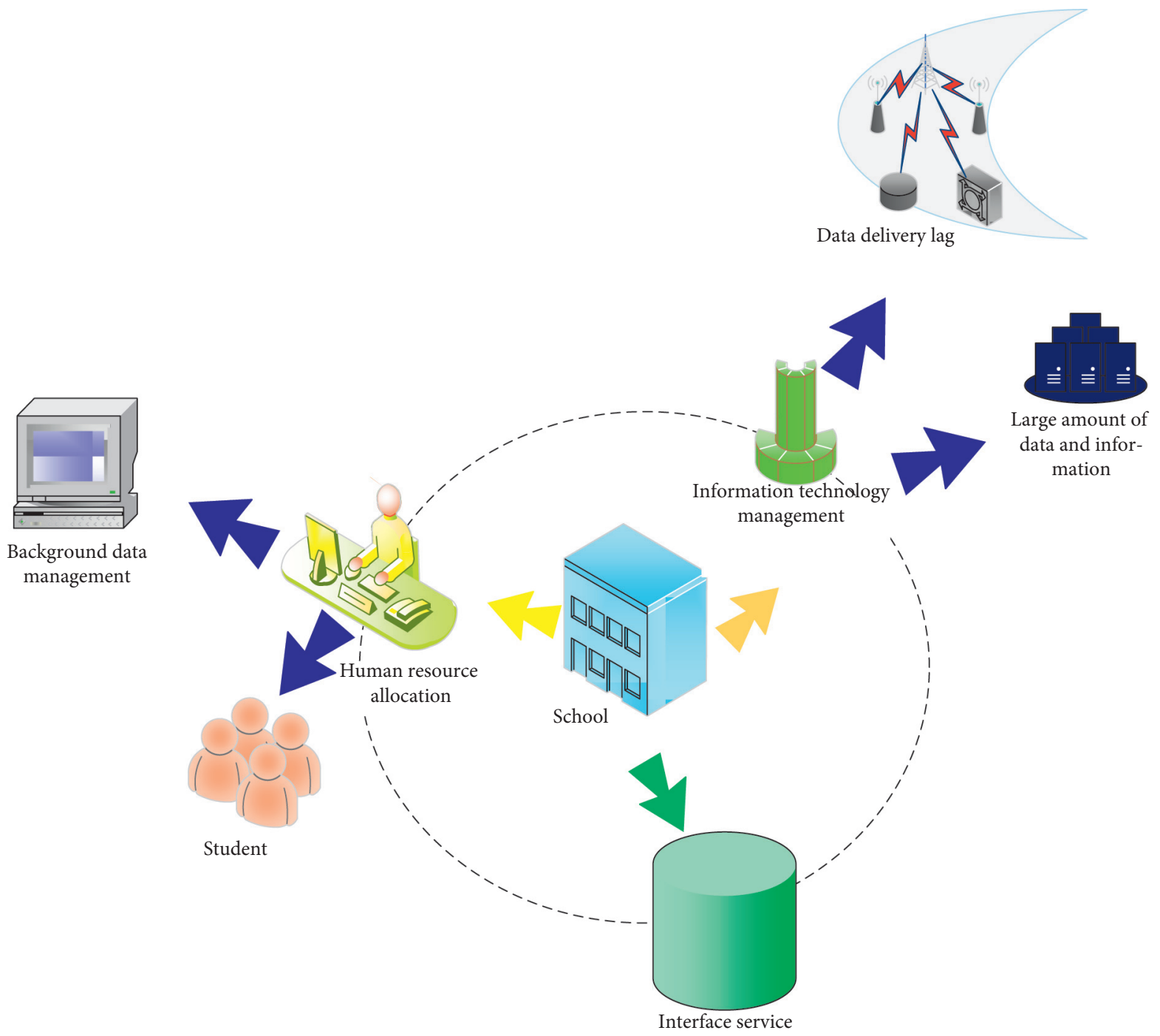

FIGURE 3: Overall architecture diagram of the online education platform.

the viewing of teaching resources and the modification and improvement of personal information. The business-level logic processing layer can closely link the presentation of the online education platform with the data support layer. The logical processing layer of the business level is also an important part of these three. It transmits the operation requirements of teachers and students to the business logic layer and further transmits the processed data to the data support layer while transmitting the data required by the teachers and students of the data support layer to the platform presentation layer. The data support layer can provide specific services such as viewing, deleting, downloading, and saving teaching resources on the online education platform. The data support layer has massive data to support the normal operation of the entire online education platform. Figure 3 shows the overall structure of the online education platform for colleges and universities.

Perform simulation experiments on the performance of the online education platform for engineering majors in colleges and universities to provide hardware support for the reform of online education courses. Figure 4 shows the specific parameters of the simulation platform.

2.2. Wireless Network Technology. In daily life, people mainly obtain external information through eye observation. However, the observation ability of the human eye is limited, and the eye is easily affected by the changing environment of the outside world. In this case, the photographic element and the image forming device are used to capture image data from the external environment. Second, the vision sensor converts the two-dimensional image into a one-dimensional electrical signal. The essence of the visual sensor is image processing technology, which captures the signal on the surface of the object and presents the image to the relevant researchers. According to different chips, visual sensors can generally be divided into Charge Coupled Device (CCD) sensors and Complementary Metal Oxide Semiconductor (CMOS) sensors. CCD uses the amount of charge to represent the signal and its transmission signal amount in the 


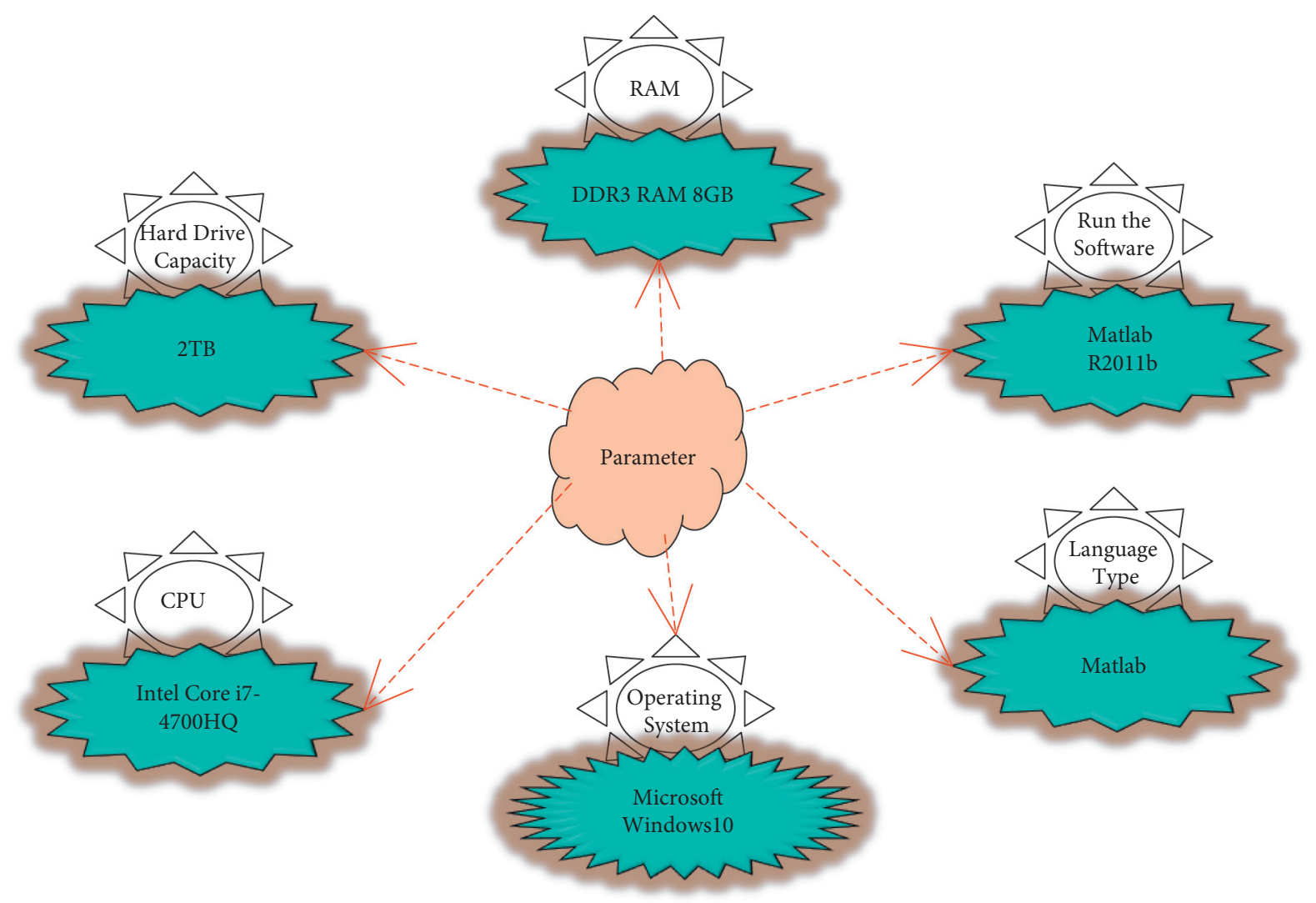

FIgURE 4: Simulation platform parameters.

coupling mode. Its specific functions include photoelectric conversion, information storage, and transmission. CCD has the advantages of automatic scanning, strong spectral sensitivity, lightweight, small distortion, small size, low system noise, low power loss, high durability, and high reliability. It can be well integrated with other elements. Linear CCD can capture one-dimensional images, while planar CCD can capture two-dimensional images, so CCD sensors have been used in various production industries. According to whether a light source is used, vision can be divided into two types: passive light vision and active light vision. The development of CMOS is mainly due to its small size, low power consumption, and low cost. But its image quality is slightly lower than CCD. Common digital products on the market mainly use CCD or CMOS. Low-end cameras mainly use CMOS, and high-end cameras use CCD. The sensor network is an indispensable part of AI. The synergy framework of the online education platform and wireless network is shown in Figure 5. Figure 5 shows the synergy between sensors and wireless network technology.

Sensor-based AI systems include college online education platforms, sensor networks, and wireless network technologies. The communication node and the central gateway node integrate the communication functions well, thus realizing the intelligent integration of college online education platform, sensor network, and wireless network technology, thus laying a solid foundation for the wireless network and online education.
Fuzzy theory can solve linear problems that are difficult to overcome by traditional theoretical systems. The basis of the fuzzy theory is the set of fuzziness, which brings together descriptions of fuzziness. For complex nonlinear problems, it is necessary to go beyond yes or no answers, and the degree of freedom of the elements of fuzzy theory solves this problem well. The fuzzy theory has signs of use in many advanced fields such as industrial control, analysis systems, and sensor systems. The general fuzzy inference system includes the processes of input and output, fuzzification, synthesis algorithm, and defuzzification. The Fuzzy C-means Algorithm clustering algorithm (FCM) [25-27] can easily solve the situation of unclear membership and difficult classification. When executing this algorithm, if the number of users is $n$ and the number of items is $m, p_{i j}$ represents the score of the $i$-th user on the $j$-th item. Let $1 \leq i \leq n, 1 \leq j \leq m$, so its evaluation matrix is shown in the following equation:

$$
P=\left[\begin{array}{cccc}
p_{11} & p_{12} & \cdots & p_{1 m} \\
p_{21} & p_{22} & \cdots & p_{2 m} \\
\vdots & \vdots & \ddots & \vdots \\
p_{n 1} & p_{n 2} & \cdots & p_{n m}
\end{array}\right]
$$

According to the evaluation matrix, the membership matrix $\mathrm{X}$ can be used to classify very similar users into $c$ clusters, as shown in the following equation: 


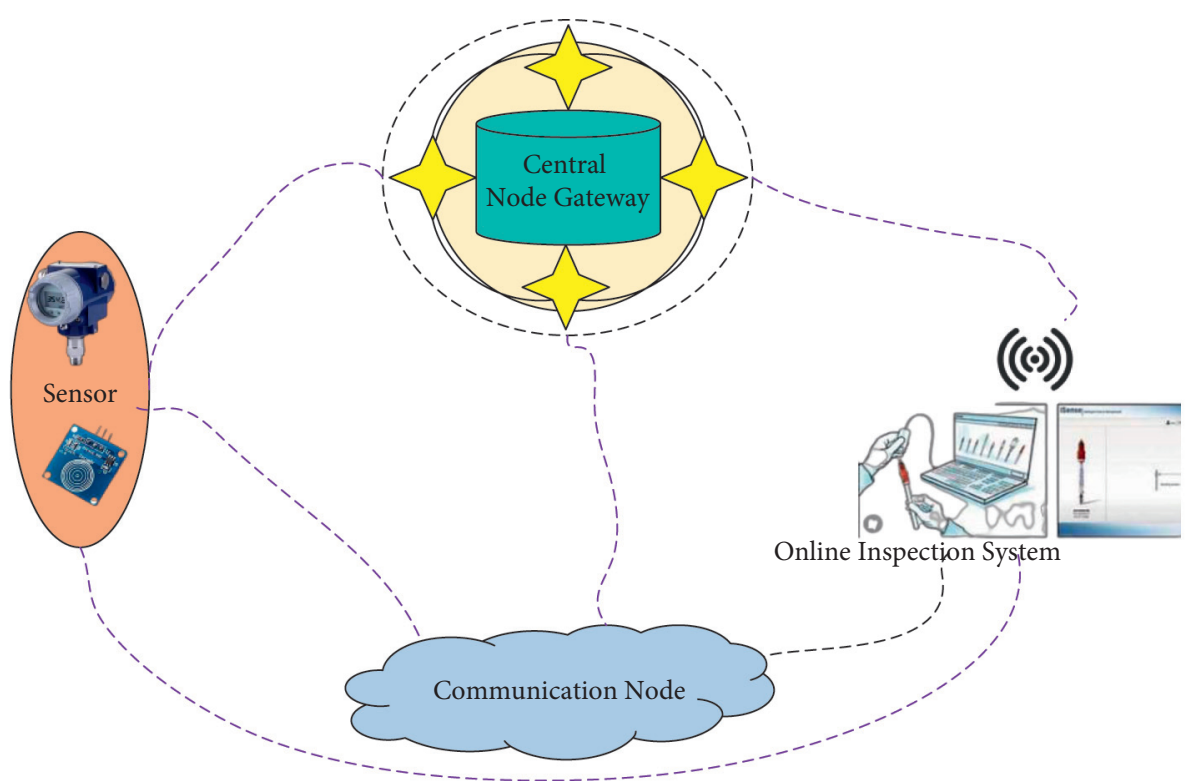

Figure 5: The synergy between sensors and wireless network technology.

$$
X=\left[\begin{array}{cccc}
x_{11} & x_{12} & \cdots & x_{1 n} \\
x_{21} & x_{22} & \cdots & x_{2 n} \\
\vdots & \vdots & \ddots & \vdots \\
x_{c 1} & x_{c 2} & \cdots & x_{c n}
\end{array}\right]
$$

Set $l$ as the fuzzy index, then $d_{i j}$ is the Euclidean distance between the $i$-th user and the $j$-th center of the cluster. To calculate the objective function of the FCM clustering algorithm [28-30], according to $n$ users and $c$ user clusters, the data of matrix $\mathrm{X}$ is used and calculated, as shown in the following equation:

$$
J_{l}(X, c)=\sum_{i=1}^{n} \sum_{j=1}^{c} x_{j i}^{l} d_{i j}^{2} .
$$

To optimize the objective function of the algorithm, it is necessary to derive its realization conditions. Assuming that there are $j(l \leq j \leq c)$ cluster centers $c_{j}$, the conditions it needs to achieve are shown in the following equations:

$$
\begin{aligned}
c_{j} & =\frac{\sum_{i=1}^{n} x_{j i}^{l} p_{i j}}{\sum_{i=1}^{n} x_{j i}^{l}}, \\
x_{j i} & =\frac{1}{\sum_{j=1}^{c}\left[d_{j i} / d_{k i}\right]^{(2 /(l-1))}} .
\end{aligned}
$$

During the execution of the algorithm, the distance from the user to the center of its cluster, the comparison of matrix data, and the reduction of similarity are often calculated. The purpose of this is to optimize the objective function. The specific steps of the algorithm are as follows: the first step is to initialize; the second step is to select the initial cluster center of the maximum density; the third step is to realize the membership matrix; the fourth step is to assume the results of the $t+1$ th and $t$-th iterations, this process satisfies the following equation:

$$
\left|J_{l}^{t+1}-J_{l}^{t}\right|<\varepsilon
$$

The membership matrix and scoring matrix when the iteration is stopped are the final solutions and then proceed to the fifth step. If the result is the opposite, execute again from the second step. The fifth step is to group users according to the membership matrix and scoring matrix to establish user clusters, to realize the classification of other users. The initial cluster canter is selected. To prevent errors in selecting the initial cluster centers and failing to complete the classification, the steps below to select the initial cluster centers during the execution process are needed to follow. The first step is that the score matrix of $n$ users is $\mathrm{P}$, then the density value of each user can be expressed by the following equations:

$$
\begin{aligned}
r_{d} & =\frac{\sqrt{(1 / n(n-1)) \sum_{j=1}^{n} \sum_{i=1}^{n}\left\|p_{i}-p_{j}\right\|^{2}}}{2}, \\
V_{i} & =\sum_{j=1}^{n} \frac{1}{1+4 /\left(r_{d}^{2}\left\|p_{i}-p_{j}\right\|^{2}\right)} .
\end{aligned}
$$

In the second step, equations (15) and (16) are used to calculate the initial cluster centers. The expression of the user's density value is shown in the following equation:

$$
V_{i}^{*}=V_{i}^{*}-V^{*} \exp \left(\frac{-\left\|p_{i}-p_{j}\right\|^{2}}{0.25 \delta_{a}}\right) \text {. }
$$

The third step is to determine the corrected initial cluster centers. If the initial cluster canter meets the equation (18), 


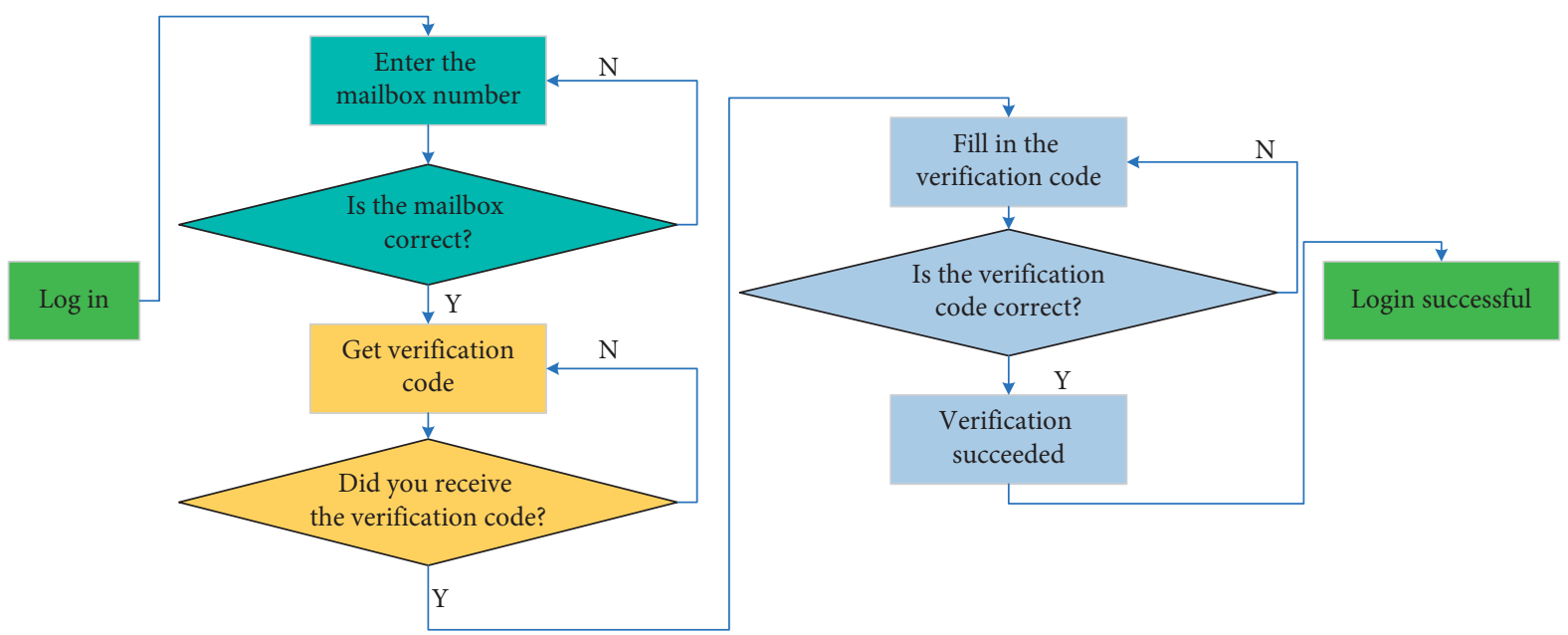

FIGURE 6: Flow chart of online education platform login.

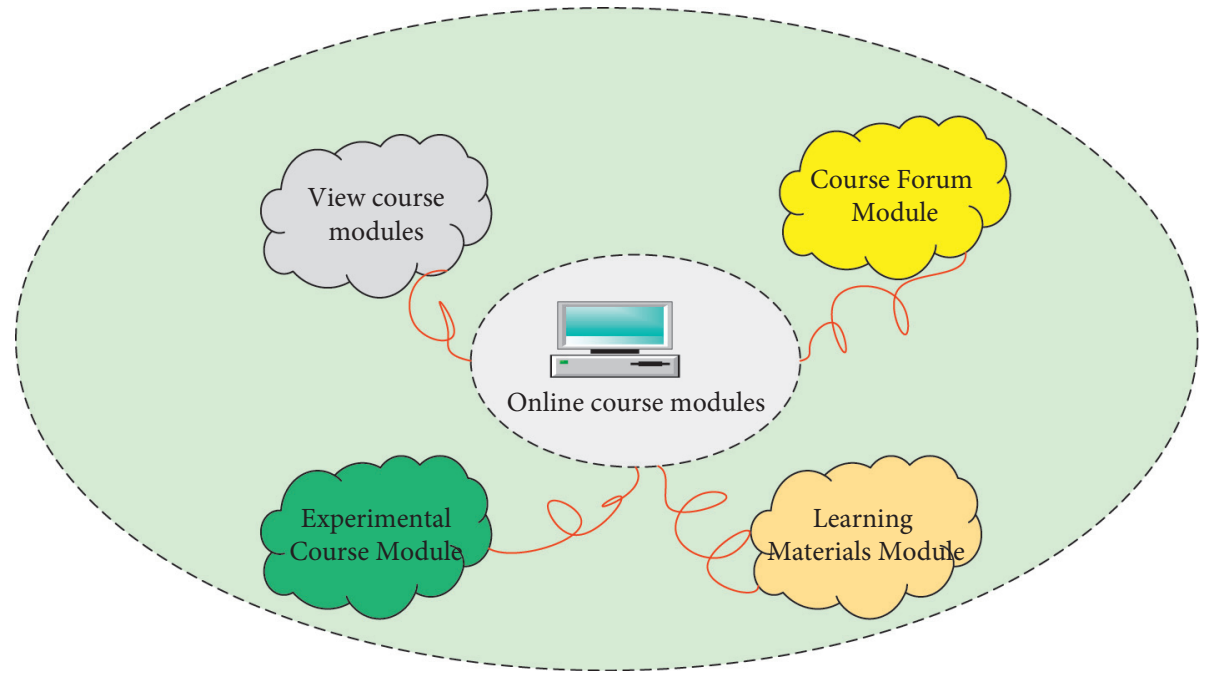

FIgURE 7: The framework of functional modules of online education courses.

then terminate the calculation; otherwise, continue to recalculate according to the first step.

$$
\frac{V_{i}^{*}}{V^{*}}<\varepsilon
$$

The fourth step is to output the initial cluster canter results. The login process steps of the online education platform of colleges and universities are briefly described. First, the online education platform for colleges and universities was logged in. The human-computer interface of the platform is opened and the mailbox number is entered to obtain the login verification code. Then, fill in the verification code and click login. Finally, check whether the login is successful. If it is unsuccessful, the above operations are repeated until it succeeds. Figure 6 shows the specific flow chart of online education platform login for engineering majors in colleges and universities.

After successfully logging in to the system of the online education platform for engineering majors in colleges and universities, the specific course modules are displayed. The online education platform studied is a trial version, so only four-course modules are selected. They are, respectively, viewing course module, course forum module, experimental course module, and learning resource module. Figure 7 is a framework diagram of specific modules of online education curriculum functions.

The online education platform system for engineering majors in colleges and universities takes case diagrams as the functional unit of the system and specifically displays the system diagram model, which can provide system participants and outreach users for observation. Participants in the online education management system of colleges and universities include the personnel management system, students, teachers, and education management. The system mainly includes four bilateral related issues, teaching plans, basic data management, service-learning applications, and teacher service applications. Figure 8 is a diagram of the interconnection architecture of the online teaching platform for teachers 


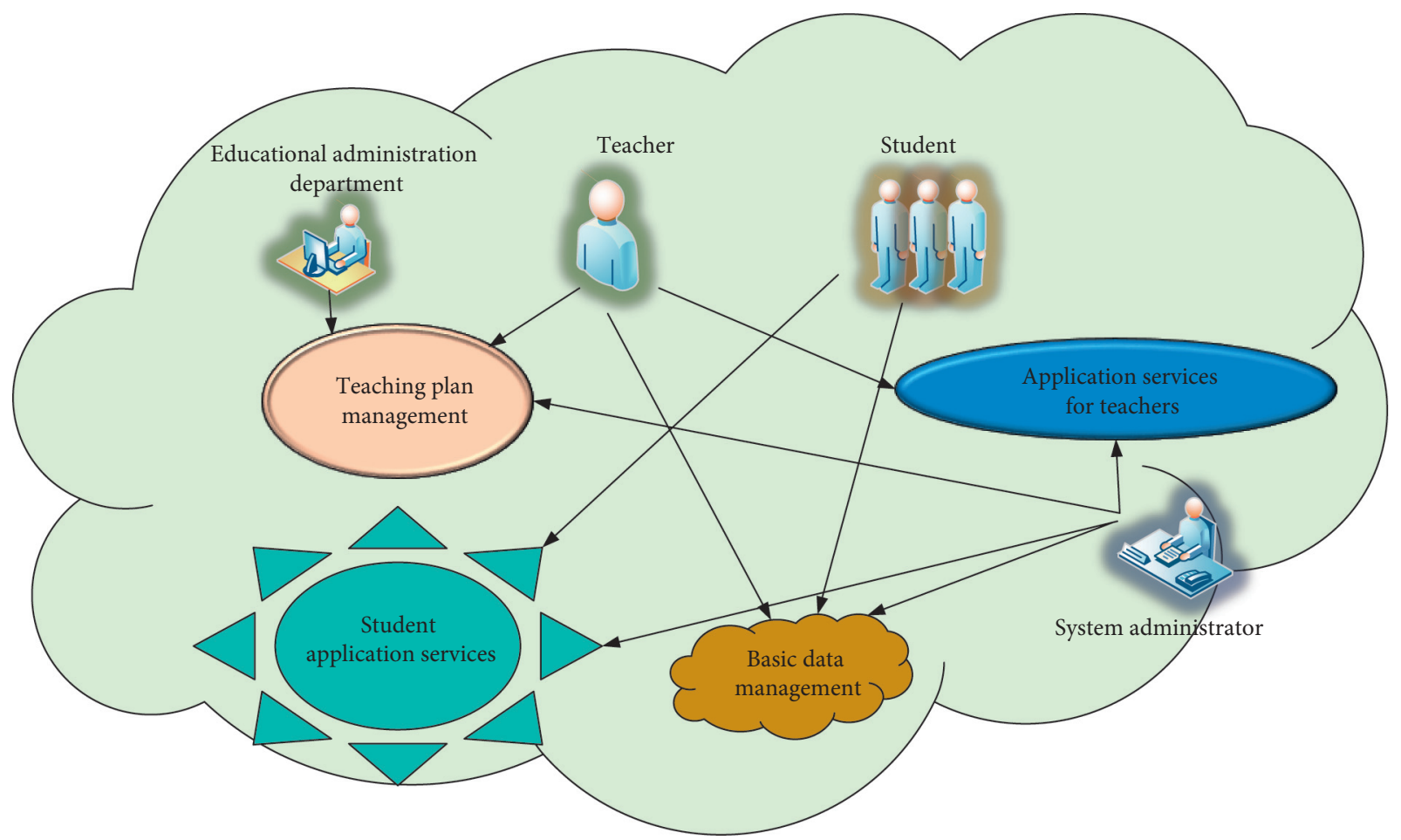

FiguRE 8: Interconnection architecture diagram of online teaching platform for teachers and students in colleges and universities.

and students of engineering majors in colleges and universities.

\section{Results}

3.1. Analysis of the Results of AI-Oriented Online Education Reform. The curriculum reform of the online education platform for engineering majors in colleges and universities has been studied. The online education platform was designed, and simulated experiments and specific data processing were carried out on the current status of online education in recent years. In 2017, quality education accounted for $2.5 \%$, civil service training accounted for $3 \%$, adult education accounted for $10 \%$, and International English Language Testing System IELTS training (IELTS) accounted for $25 \%$. In 2018, quality education accounted for $4.5 \%$, civil service training accounted for $5 \%$, adult education accounted for $10 \%$, and IELTS accounted for 30\%. In 2019, quality education accounted for $5 \%$, civil service training accounted for $10 \%$, adult education accounted for $15 \%$, and IELTS accounted for $30 \%$. In 2020, quality education will account for $20 \%$, civil service training will account for $15 \%$, adult education will account for $25 \%$, and IELTS will account for $45 \%$. In 2021, quality education will account for $15 \%$, civil service training will account for $20 \%$, adult education will account for $25 \%$, and IELTS will account for $40 \%$. From the above data, it is obvious that quality education, civil service training, adult education, and IELTS have been on the rise in the ranks of online education. However, the overall share is a decline in 2021. Figure 9 shows the specific situation of online education development in different years.
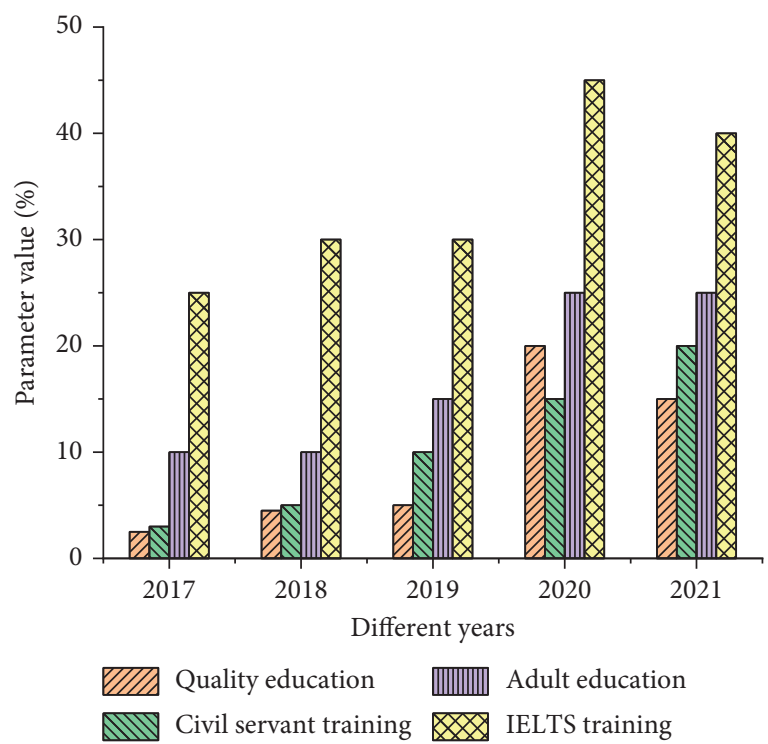

FIGURE 9: The development of online education in different years.

According to the specific data situation of the online teaching platform request processing time, the overall response time of the designed platform to university teachers and students is controlled within $3 \mathrm{~s}$. For the first simulation test, the minimum request processing time of the online teaching platform is $0.23 \mathrm{~s}$, the average value is $0.12 \mathrm{~s}$, the median value is $1.6 \mathrm{~s}$, and the maximum value is $3 \mathrm{~s}$. In the second simulation test, the minimum value of the online teaching platform request processing time is $0.25 \mathrm{~s}$, the average value is $0.14 \mathrm{~s}$, the median value is $1.7 \mathrm{~s}$, and the 


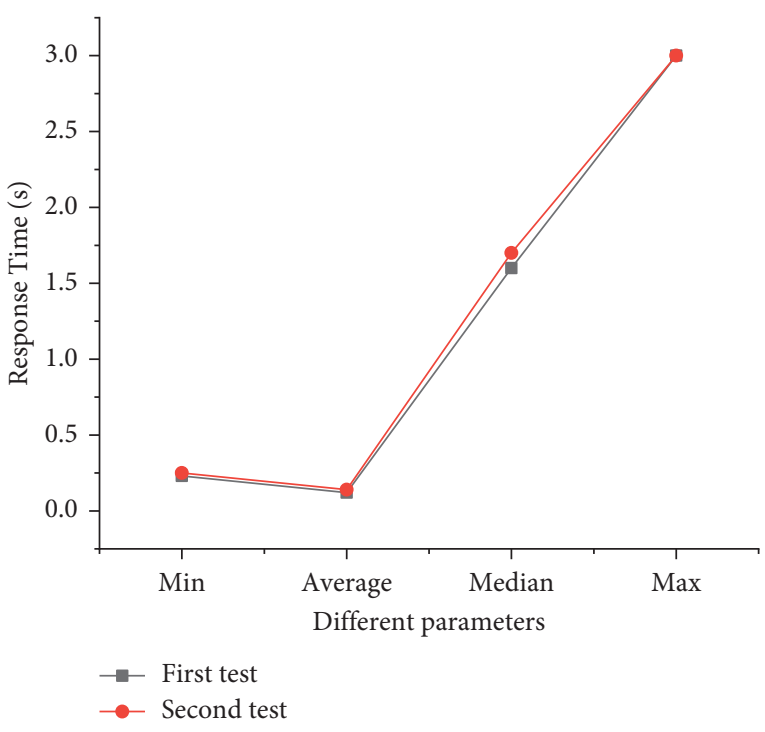

FIGURE 10: Data of request processing time of the online teaching platform.

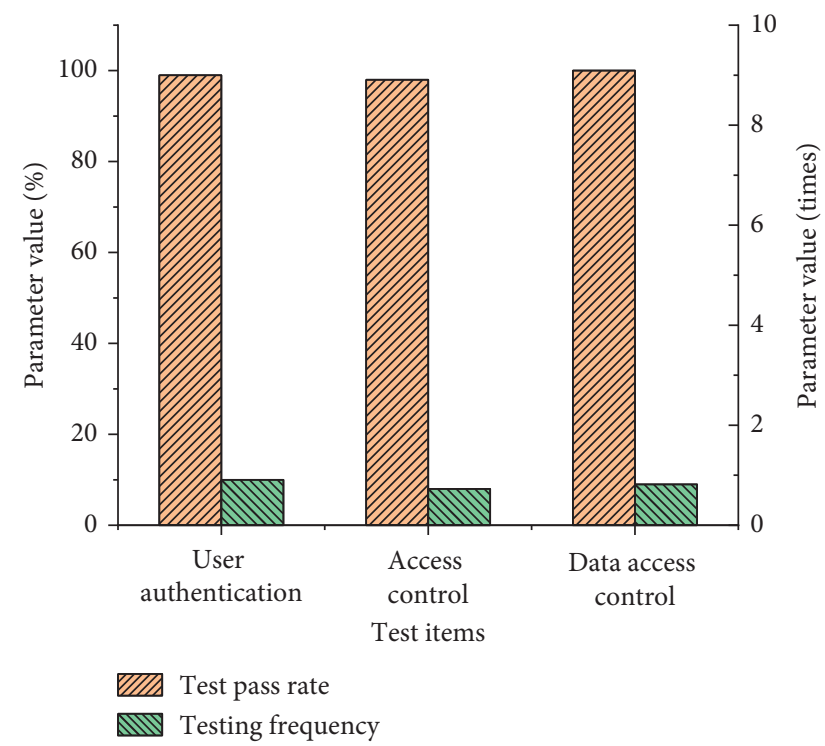

Figure 11: Security test data diagram of an online education platform.

maximum value is $3 \mathrm{~s}$. In the two tests of the online education platform, the two sets of data are very close. Therefore, the performance of this online education platform is relatively stable, and the platform provides hardware support for online course reform. Figure 10 presents the data of request processing time of an online teaching platform.

\subsection{Analysis of Online Education Reform Using Wireless} Network Technology. According to the data situation of the online education platform security test, the following results are obtained. In terms of the number of tests, the number of user authentication for teachers and students is 10, the number of accesses to the system is 8 times, and the number of data access control is 9 times. In terms of test pass rate, the pass rate of teacher and student user authentication is $99 \%$, the pass rate of access to the system is $98 \%$, and the pass rate of data access control is $100 \%$. After many tests, the pass rate of the online education platform security test is above $98 \%$, as shown in Figure 11.

\section{Conclusions}

With the continuous development of science and technology, the speed of social progress is getting faster and faster, and the level of education in China is getting higher and higher. These changes and developments are inseparable from the promotion of online education platforms. Today's education methods have gradually shifted from the traditional physical classroom education model to an intelligent and scientific model. With the acceleration of China's education reform, online education platforms have gradually become a new trend of the times. Under the trend of this new era, the reform of online education courses for engineering majors in colleges and universities has become the focus of research. AI technology and wireless network technology are used here to conduct in-depth design and research on online education courses for engineering majors in colleges and universities. AI-oriented online education reform can w0ell solve various problems existing in online education course platforms, especially when the course resources of online education platforms are not detailed enough, and the effect of monitoring students' learning is not good. The innovation is that AI's wireless network technology is used in online education curriculum reform research. The combination of AI and wireless network technology is the novelty of this research. This provides theoretical support for the reform of online education courses. It has a very important meaning. The research results show that the overall response time of this platform to university teachers and students is controlled within $3 \mathrm{~s}$. The two test results of the online education platform show that the performance of the online education platform is relatively stable, which provides hardware support for the reform of online courses. In addition, in terms of the platform test pass rate, the pass rate of the online education platform security test after multiple tests is above 98\%. The following conclusions are drawn: AI technology and wireless network technology can effectively improve the performance of online education platforms and can further improve the learning efficiency of online education courses for college engineering students. The shortcomings are that the selection of indicators for online education platforms is not comprehensive enough, and the data collection is too narrow, which has a certain impact on the universality of this paper. In future research, it is necessary to minimize the impact of data collection on research results. In the next work, deep learning and Internet of Things technology will be combined to further study the reform of online education courses.

\section{Data Availability}

The data that support the findings of this study are available from the corresponding author upon reasonable request. 


\section{Conflicts of Interest}

The authors declare that they have no conflicts of interest.

\section{Acknowledgments}

This research was funded by Key Projects of Higher Education Reform in Heilongjiang Province "Reform and Practice of Talent Training Program for Electronic Information Specialty of Application-Oriented Undergraduate under the Background of Engineering Certification" (Project No. SJGY20200100).

\section{References}

[1] P. Redmond, L. A. Abawi, and A. Brown, "An online engagement framework for higher education," Online Learning, vol. 22, no. 1, pp. 183-204, 2018, https://files.eric.ed.gov/ fulltext/EJ1179626.pdf.

[2] B. E. Penprase, "The fourth industrial revolution and higher education," Higher Education in the Era of the Fourth Industrial Revolution, vol. 10, pp. 978-981, 2018.

[3] A. R. Saravanakumar and K. R. Padmini Devi, "Indian higher education: issues and opportunities," Journal of Critical Reviews, vol. 7, no. 2, pp. 542-545, 2020.

[4] X. B. Liu and L. I. Xin, "Construction of integrative case teaching system of mechanical engineering specialty under engineering certification education," Value Engineering, vol. 34, p. 99, 2018.

[5] H. Li and X. Shi, "Calculating and evaluating of the achievements of pharmaceutical separation engineering course for pharmaceutical engineering major based on engineering education certification," Indian Journal Of Pharmaceutical Education and Research, vol. 54, no. 1, pp. 17-21, 2020.

[6] D. Nurdianto and S. Ahmad, "To evaluate the performance of certification competence vocational students through certification institute profesi-P1 program computer engineering expertise and tissues at South Sumatra," Jurnal Pendidikan Tambusai, vol. 5, no. 1, pp. 2370-2373, 2021.

[7] M. Schophuizen, K. Kreijns, S. Stoyanov, and M. Kalz, "Eliciting the challenges and opportunities organizations face when delivering open online education: a group-concept mapping study," The Internet and Higher Education, vol. 36, pp. 1-12, 2018.

[8] L. Mishra, T. Gupta, and A. Shree, "Online teaching-learning in higher education during lockdown period of COVID-19 pandemic," International Journal of Educational Research Open, vol. 1, Article ID 100012, 2020.

[9] F. Farooq, F. A. Rathore, and S. N. Mansoor, "Challenges of online medical education in Pakistan during COVID-19 pandemic," Journal of the College of Physicians and Surgeons-Pakistan: JCPSP, vol. 30, no. 6, pp. 67-69, 2020.

[10] Y. Jung and J. Lee, "Learning engagement and persistence in massive open online courses (MOOCS)," Computers \& Education, vol. 122, pp. 9-22, 2018.

[11] E. Kim, H. Park, and J. U. Jang, "Development of a class model for improving creative collaboration based on the online learning system (moodle) in Korea," Journal of Open Innovation: Technology, Market, and Complexity, vol. 5, no. 3, p. $67,2019$.

[12] J. E. Nieuwoudt, "Investigating synchronous and asynchronous class attendance as predictors of academic success in online education," Australasian Journal of Educational Technology, vol. 36, no. 3, pp. 15-25, 2020.

[13] S. Palvia, P. Aeron, P. Gupta et al., "Online education: worldwide status, challenges, trends, and implications," Journal of Global Information Technology Management, vol. 21, no. 4, pp. 233-241, 2018.

[14] W. Villegas-Ch, M. Román-Cañizares, and X. PalaciosPacheco, "Improvement of an online education model with the integration of machine learning and data analysis in an LMS," Applied Sciences, vol. 10, no. 15, p. 5371, 2020.

[15] P. Chakraborty, P. Mittal, M. S. Gupta, S. Yadav, and A. Arora, "Opinion of students on online education during the COVID-19 pandemic," Human Behavior and Emerging Technologies, vol. 3, no. 3, pp. 357-365, 2021.

[16] C. Chen, K. T. Jones, and K. Moreland, "How online learning compares to the traditional classroom: measuring accounting course outcomes," The CPA Journal, vol. 87, no. 9, pp. 44-47, 2017.

[17] X. Liu, J. Zhou, L. Chen, Y. Yang, and J. Tan, "Impact of COVID-19 epidemic on live online dental continuing education," European Journal of Dental Education, vol. 24, no. 4, pp. 786-789, 2020.

[18] E. A. Danchikov, N. A. Prodanova, Y. N. Kovalenko, and T. G. Bondarenko, "The potential of online learning in modern conditions and its use at different levels of education," Linguistics and Culture Review, vol. 5, no. S1, pp. 578-586, 2021.

[19] N. Xu and Y. Zhao, "Online education and wireless network coordination of electronic music creation and performance under artificial intelligence," Wireless Communications and Mobile Computing, vol. 2021, Article ID 5999152, 9 pages, 2021.

[20] J. Vithayathil, "Will cloud computing make the Information Technology (IT) department obsolete?" Information Systems Journal, vol. 28, no. 4, pp. 634-649, 2018.

[21] B. Varghese and R. Buyya, "Next generation cloud computing: new trends and research directions," Future Generation Computer Systems, vol. 79, pp. 849-861, 2018.

[22] Y. Xiong and H. K. Suen, "Assessment approaches in massive open online courses: possibilities, challenges and future directions," International Review of Education, vol. 64, no. 2, pp. 241-263, 2018.

[23] J. M. Weinhardt and T. Sitzmann, "Revolutionizing training and education? three questions regarding massive open online courses (MOOCs)," Human Resource Management Review, vol. 29, no. 2, pp. 218-225, 2019.

[24] A. D. Dumford and A. L. Miller, "Online learning in higher education: exploring advantages and disadvantages for engagement," Journal of Computing in Higher Education, vol. 30, no. 3, pp. 452-465, 2018.

[25] A. K. Dubey, U. Gupta, and S. Jain, "Comparative study of $\mathrm{K}$-means and fuzzy C-means algorithms on the breast cancer data," International Journal of Advanced Science, Engineering and Information Technology, vol. 8, no. 1, pp. 18-29, 2018.

[26] A. Rajput and V. B. Kumaravelu, "Scalable and sustainable wireless sensor networks for agricultural application of Internet of things using fuzzy c-means algorithm," Sustainable Computing: Informatics and Systems, vol. 22, pp. 62-74, 2019.

[27] A. M. Anter and M. Ali, "Feature selection strategy based on hybrid crow search optimization algorithm integrated with chaos theory and fuzzy c-means algorithm for medical diagnosis problems," Soft Computing, vol. 24, no. 3, pp. 1565-1584, 2020. 
[28] Y. Zhao, J. Xu, and J. Wu, "A new method for bad data identification of oilfield system based on enhanced gravitational search-fuzzy C-means algorithm," IEEE Transactions on Industrial Informatics, vol. 15, no. 11, pp. 5963-5970, 2019.

[29] Z. Liang, C. Wang, S. Han, K. Ullah Jan Khan, and Y. Liu, "Classification and susceptibility assessment of debris flow based on a semi-quantitative method combination of the fuzzy C-means algorithm, factor analysis and efficacy coefficient," Natural Hazards and Earth System Sciences, vol. 20, no. 5, pp. 1287-1304, 2020.

[30] L. Wan, T. Zhang, Y. Xiang, and H. You, "A robust fuzzy c-means algorithm based on bayesian nonlocal spatial information for SAR image segmentation," IEEE Journal of Selected Topics in Applied Earth Observations and Remote Sensing, vol. 11, no. 3, pp. 896-906, 2018. 